\title{
RESEARCH OF TRANSPORT AND DEPOSITION OF AEROSOL IN HUMAN AIRWAY REPLICA
}

\author{
Frantisek LIZAL ${ }^{1}$, Jan JEDELSKY, Jakub ELCNER, Lukas DURDINA, Tereza HALASOVA², \\ Filip MRAVEC, Miroslav JICHA
}

\begin{abstract}
Growing concern about knowledge of aerosol transport in human lungs is caused by great potential of use of inhaled pharmaceuticals. Second substantial motive for the research is an effort to minimize adverse effects of particular matter emitted by traffic and industry on human health.

We created model geometry of human lungs to 7 th generation of branching. This model geometry was used for fabrication of two physical models. The first one is made from thin walled transparent silicone and it allows a measurement of velocity and size of aerosol particles by Phase Doppler Anemometry (PDA). The second one is fabricated by stereolithographic method and it is designed for aerosol deposition measurements. We provided a series of measurements of aerosol transport in the transparent model and we ascertained remarkable phenomena linked with lung flow. The results are presented in brief. To gather how this phenomena affects aerosol deposition in human lungs we used the second model and we developed a technique for deposition fraction and deposition efficiency assessment.

The results confirmed that non-symmetric and complicated shape of human airways essentially affects transport and deposition of aerosol. The research will now focus on deeper insight in aerosol deposition.
\end{abstract}

\section{INTRODUCTION}

Research of transport and deposition of aerosols (gas borne suspensions of liquid or solid particles) in human lungs is conducted by three different approaches. On human volunteers, i.e. in vivo, on human airway replicas, i.e. in vitro and using computational fluid dynamics (CFD), i.e. in silico. We focused on in vitro and in silico methods. This paper deals with experimental measurement of velocity and size of aerosol particles in transparent realistic model of human airways and with experimental measurements of aerosol deposition in segmented realistic model. Our results will contribute to more efficient drug delivery through inhalation route. It is expected that drug

\footnotetext{
${ }^{1}$ Frantisek Lizal, Jan Jedelsky, Jakub Elcner, Lukas Durdina, Miroslav Jicha, Brno University of Technology, Faculty of Mechanical Engineering, Technicka 2, 61669 Brno, Czech Republic, ylizal00@stud.fme.vutbr.cz

2 Tereza Halasova, Filip Mravec, Brno University of Technology, Faculty of Chemistry, Purkynova 118, 61200 Brno, Czech Republic, xchalasova@fch.vutbr.cz
}

This is an Open Access article distributed under the terms of the Creative Commons Attribution License 2.0, which permits unrestricted use, distribution, and reproduction in any medium, provided the original work is properly cited. 
administration by inhalation will be used increasingly. The inhalation route could be used not only for the treatment of asthma or COPD, but also for other diseases. For example antibiotics could be inhaled for the treatment of cystic fibrosis [22] or insulin could be inhaled by diabetics [24].

Key feature for in vitro measurements is a type of model geometry selected. First models available since 1970 s were idealized symmetric Weibel A model [27] and asymmetric Horsfield model [13], or later Raabe model [20]. Common feature of all these idealized models was neglecting of surface irregularities, physiological traits, protuberances and roughness of the surface. With onset of imaging methods (Computed Tomography, CT and Magnetic Resonance Imaging, MRI) realistic models became available. An example of such model are CT models published by Hopkins et al. [12] or Clinkenbeard et al. [5], MRI model was used by Guilmette et al. [10].

First method used for measurement of flow velocity in human lung models was Hot Wire Anemometry. The most detailed work was published in three papers by Chang et al. [3], Isabey et al. [14] and Menon [18]. In the first part of their work they measured the steady inspiration and expiration in semi-realistic models to 3 - 4 generation of branching at a scale of 3:1 in twelve sections. Their main conclusions were that airway geometry influences the shape of the velocity profile far more than the Reynolds number. Glottis affects the shape of the velocity profile only in the immediate vicinity; its influence in the subsequent generation is negligible. Measurements were provided on the model without mucus. They argue that the presence of mucus on the wall itself does not cause substantial change in velocity profile. Separation of the flow was observed only in the upper bronchus.

In the second part of their work they used a slanted hot-wire probe to measure the
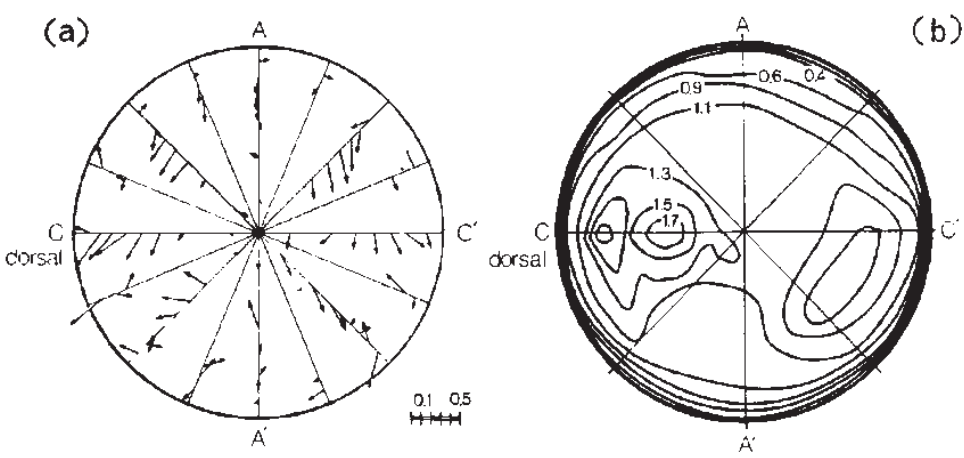

Figure 1 Secondary velocity during expiration upward the first bifurcation. Source: [14] secondary velocity (tangential and radial) (see

Fig. 1). Secondary velocity never exceeded $21.5 \%$ axial velocity. The third part of the work deals with oscillatory velocity profiles in the same model geometry. Authors themselves derived, that the results have limited validity with regard to physiological conditions and they recommend extending

the model a few generations to fit the physiological conditions.

Several teams deal with an in vitro research of flow field by optical methods. The most commonly used method is Particle Image Velocimetry (PIV). This method was used e.g. by Adler et al. [1], Brücker et al. [2] or Ramuzat and Riethmüller [21]. Transparent models are precondition of all these studies. The problem with optical distortion is commonly solved by use of glycerine and water mixture as a carrier medium for particles. Disadvantage of this method is impossibility of direct aerosol velocity measurement. Laser Doppler Velocimetry (LDV) method allows such measurements. Nevertheless the first LDV measurements were provided with glycerine by Corrieri and Riethmüller [8] in 1989 on highly idealized $Y$ shape model. $Y$ shaped models were used in 
1998 also by Peatie and Schwarz [19] and in the same year by Lieber and Zhao [16]. Their main conclusions were that secondary velocities are lower when cyclic breathing regime is used compared to static flowrates and that the quasi-stationary assumption is valid just for about $40 \%$ of the breathing cycle. Horsfield idealized geometry was used by Tanaka et al. [25]. Their results showed that the secondary velocity depends not only on the branching angle and curvature of the tube, but very strongly on the shape of the previous branching.

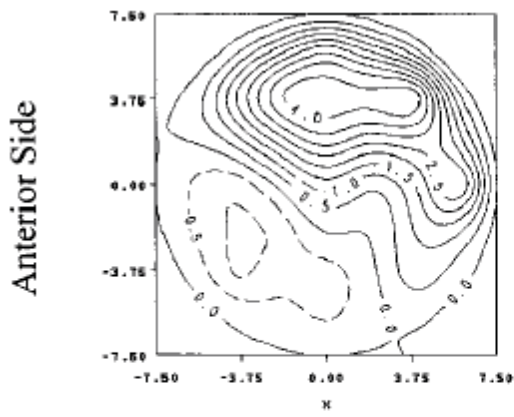

\section{Cadaver Model not Including Carina}

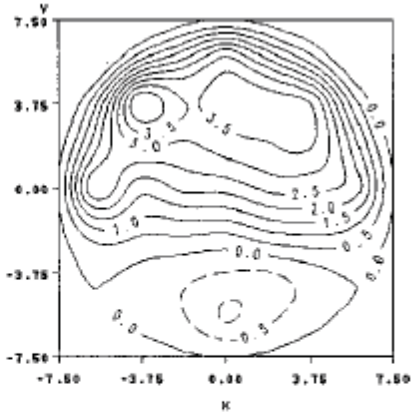

Cadaver Model Including Carina

Figure 2 Velocity contours downstream of the glottal constriction from two different models with and without casting of carina. Source: [25]

Anemometry (PDA) was
used again by Corcoran and Chigier [7] and later Gemci et al. [9]. Measurements were conducted on a glass cylinder, which contained a triangular slot as a simulation of vocal cords. Results were compared with numerical simulation. Authors evidenced recirculation below the vocal cords. They also measured increased intensity of turbulence at the top of the trachea, which they put in the context with increased deposition mentioned in the literature.

Numerous studies were provided to ascertain aerosol deposition in human airways. A lot of them were devoted to nasal deposition, but also tracheobronchial deposition was investigated on models to $4^{\text {th }}$ generation of branching. Work of Gurman et al. [11], Zhou et al. [28] and Cheng et al. [4] could be used as an example. Local deposition is influenced by five basic deposition mechanisms: Interception, inertial impaction, gravitational sedimentation, diffusion and electrostatic precipitation. The mechanism of interception asserts when the particle get close to the wall and deposits on it. A major role is played by the geometric shape of particles. Inertial impaction is the main mechanism of deposition in upper airways, where sharp changes in airway direction are present, so heavier particles cannot follow the streamlines and continue in the original direction. This explains the local deposition hot spots near the carina. Sedimentation is the mechanism, which applies in bronchioles and alveolar area at low velocities on the contrary. Diffusion mechanism, by which particles of the smallest size are deposited, is registered throughout the lungs and is associated with the intensity of turbulence. Electrostatic precipitation is applied despite the fact that the lungs do not have their own charge. When charged particles approach the wall, a mirror voltage is created on the 
wall, and hence attractive forces raise that allow the deposition. In most cases it is sufficient to consider the inertial impaction, sedimentation and diffusion [17].

\section{TRANSPARENT REALISTIC MODEL OF HUMAN AIRWAY}

Based on the literature survey, it was decided to study the transport and deposition of aerosol in a realistic model. The final geometry was created by merging of the geometry published by Schmidt et al. [23], which contains the airways from the trachea up to $17^{\text {th }}$ generation of branching with geometry of larynx and trachea obtained by CT in St. Anna University Hospital in Brno. Obtaining full geometry using the CT scan failed because of poor image quality due to movements caused by a heartbeat. Schmidt's model was obtained in a data format containing coordinates of nodes, links between them and branch diameters. The data were processed by the "marching cube" algorithm into a vector model with polygonal net. The resulting model was smoothed in software Rhinoceros (McNeel) and converted into stereolitographic format (STL). Data processing

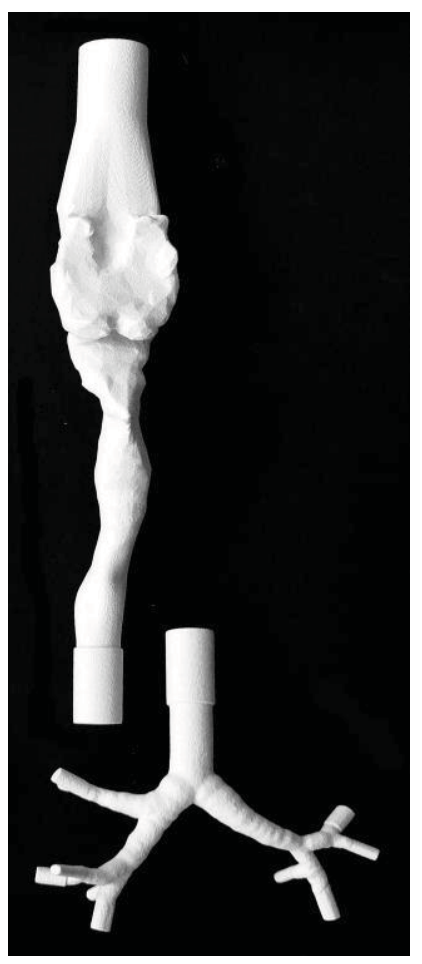

Figure 3 The core of the transparent model

and merging of models was made by Premysl Krsek from the Institute of Computer Graphics and Multimedia FIT BUT. Transparent model for optical measurements has only four generations of branching, as the following bronchi have too small diameter (2-4 $\mathrm{mm})$ with respect to the PDA measuring volume. However, it is possible to extend the model with nontransparent segments of the model for deposition measurements described in chapter 5 .

The methodology of fabrication was inspired by Hopkins et al. [12]. However, our methodology differs in many respects, due to the unavailability of certain materials, and requirements of thin-walled model. Rapid Prototyping Technology, 3-D printing machine ( $Z$ Printer

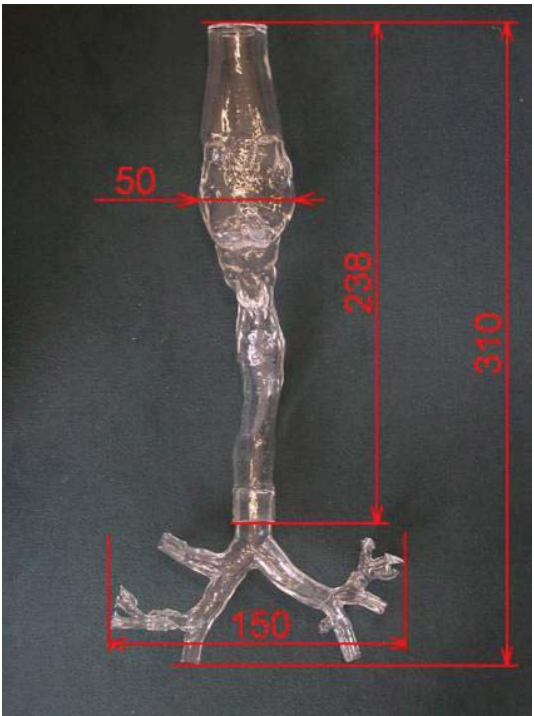

Figure 4 The transparent model of human airway

310, Z Corporation Company) was used for fabrication of a model core (negative) made of materials MD 102 or MD 130 (see Fig. 3). Machine resolution is $0.1 \mathrm{~mm}$. For practical reasons, the model is divided into two parts, which are then assembled after the fabrication. The core surface was coated by several layers of water soluble polyvinyl alcohol (PVA) separator. Afterwards a transparent silicone Sylgard 184 (Dow Corning) was applied. The model was cured for 10 minutes at $150{ }^{\circ} \mathrm{C}$ after applying of each layer of silicone, heating to $150{ }^{\circ} \mathrm{C}$ lasted 20 min. The total thickness of silicon is $1 \mathrm{~mm}$ at the output branches and $4 \mathrm{~mm}$ at the model input. After curing the last layer of silicone the core was dissolved by water. Special nozzle was used to facilitate the removal of the core. Model dimensions are shown in Fig. 4. The model was then fitted into a specially designed frame so that the 
hose could be easily attached to the model inlet and outlets are connected to a mechanism that simulates breathing. The frame was attached to traversing mechanism that allows movement of the model with accuracy better than $0.25 \mathrm{~mm}$.

\section{EXPERIMENTAL SETUP FOR PHASE DOPPLER ANEMOMETRY MEASUREMENTS}

Three breathing patterns were simulated by pneumatic cylinder with a piston (Hoerbiger NZK 6100-0400 AG), which is driven by a motor (TG Drives TGH3). The motor is computer controlled. Any course of piston movement (a sine wave course was used, which is most common for studies of aerosol transport in human lung), as well as tidal volume (up to 3 litre) and period (up to $0.1 \mathrm{~s}$ ) can be set. The mechanism has a trigger output, which synchronises PDA measurement with a piston movement.

Condensation monodisperse aerosol generator TSI 3475 (CMAG) was used and verification of suitable operating regimes was provided. The generator is based on principle of heterogeneous condensation. Vapours of suitable material (di-2-ethylhexyl sebacate (DEHS) was used in this case) condense in a controlled manner on small particles of sodium chloride, which serve as condensation nuclei [26]. This enables to obtain relatively high concentrations $\left(10^{6} \mathrm{P} / \mathrm{cm}^{3}\right)$ of monodisperse particles. Particles with aerodynamic diameter between $0.1 \mu \mathrm{m}$ to $8 \mu \mathrm{m}$ can be generated.

Velocity and size measurement of the particles during breathing cycle are made using Dantec P/DPA. This 1D system is equipped with Ar-Ion+ Laser ILT 5500A-00 (max. power $300 \mathrm{~mW}$ ). Spectral line $514.5 \mathrm{~nm}$ of the CW laser beam with power up to $90 \mathrm{~mW}$ and horizontal polarization is split using transmitting optics $58 \mathrm{~N} 10$ into 2 parallel beams $60 \mathrm{~mm}$ distant. Frequency of one of the beams is shifted by $40 \mathrm{MHz}$. Beam diameter is expanded to $2.5 \mathrm{~mm}$ to reduce a probe volume. The transmitting lens focal length is 310 $\mathrm{mm}$. Light refracted by the 1st order is collected using receiving optics 57X10 equipped with three photo-detectors. Focal length of receiving lens is $310 \mathrm{~mm}$ and scattering angle $45^{\circ}$ used. Signal processor Dantec 58N50 enabled measurement of velocity in range -8 to $24 \mathrm{~m} / \mathrm{s}$ at $12 \mathrm{MHz}$ bandwidth and in range -2.7 to $8.0 \mathrm{~m} / \mathrm{s}$ at $4 \mathrm{MHz}$ bandwidth. Maximum droplet size is $44.9 \mu \mathrm{m}$. The obtained data are evaluated using BSA Flow Software v2.1.

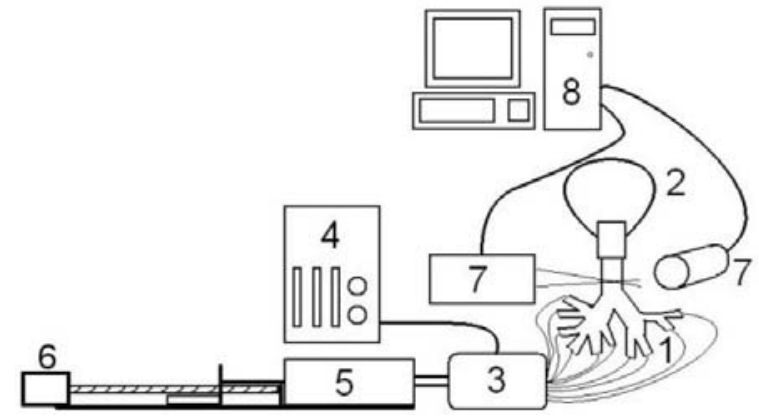

Figure $5 \mathrm{~A}$ scheme of the test rig for measurement of deposition

The scheme of a test rig is in Fig. 5. Model 1 is located in a frame that is attached to the traversing mechanism. Elastic bag 2 is connected to the model input to prevent the leakage of aerosol into the environment, and to ensure enough aerosol for both phases of breathing cycle. Aerosol from aerosol generator 4 is mixed with air from a pneumatic mechanism 5 driven by computer controlled motor 6 in a static mixer 3. Transmitting and receiving optics 7 measures the velocity and size of particles and measured data is processed by computer 8 .

If the measurement is provided in a transparent cylinder with laser beams impinging perpendicularly, special method for finding the actual measuring site should be used. At 
first left and right wall is to be located using laser beams. Than the beams are moved into the middle between left and right wall, so they pass perpendicular to the cylinder wall. Accurate matching of cylinder inner walls lengthwise laser beams then follows. The centre of the cylindrical tube is then in the middle of two cross-sections of laser beams with the wall. This point is set as $[0,0]$ and lies on the axis of the tube.

With respect to actual wall irregularity the laser beams could be slightly deflected and have to be adjusted manually. Practically, this adjustment was unavoidable in every measuring point to achieve satisfactory data rate.

Measurement was provided with particles in sizes $1 \mu \mathrm{m}, 3 \mu \mathrm{m}$ and $6 \mu \mathrm{m}$. Three cyclic breathing patterns were set: resting conditions (tidal volume $V_{t}=0.5$ litre, period $T=$ $4 \mathrm{~s})$, deep breath $\left(V_{t}=1.0\right.$ litre, $\left.T=4 \mathrm{~s}\right)$ and light activity $\left(V_{t}=1.5\right.$ litre, $\left.T=3 \mathrm{~s}\right)$. All regimes were measured with $3 \mu \mathrm{m}$ particles, $1 \mu \mathrm{m}$ and $6 \mu \mathrm{m}$ particles were measured just in the deep breath regime.

\section{RESULTS ACQUIRED BY PDA}
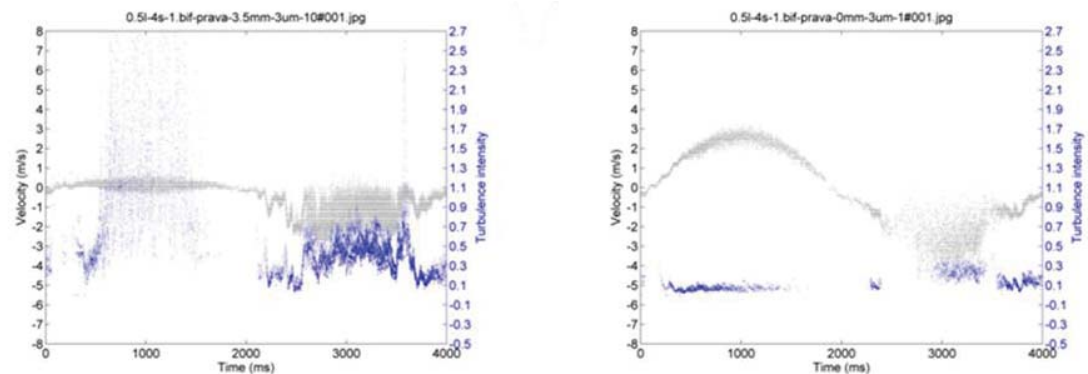

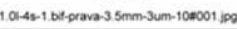
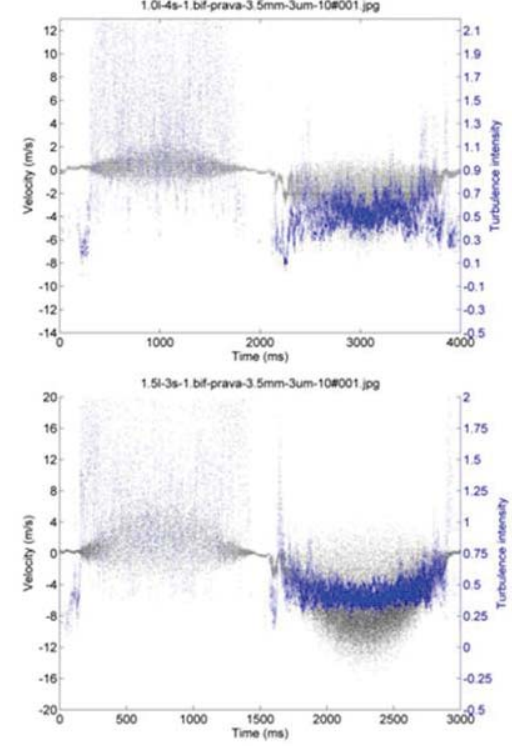

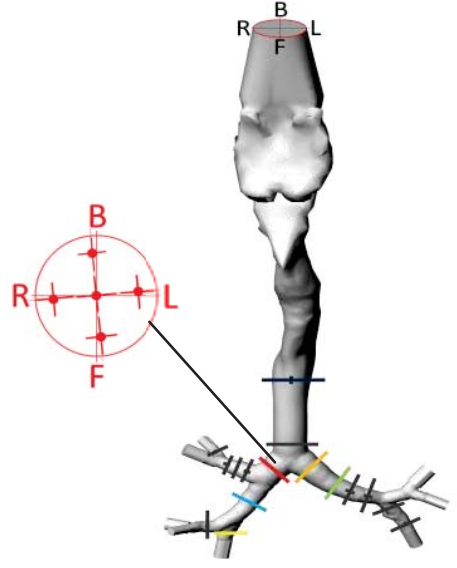

Figure 6 Measured crossections of the model

Figure 7 Velocity and intensity of velocity fluctuations in right bronchus, first bifurcation, left: upper point near the bifurcation, right: centreline

PDA measurements were provided in 16 cross-sections of the model. It is obvious that intensity of velocity fluctuations is higher during expiration, due to mixing of airflow from daughter branches. It was also evidenced that velocity courses are highly dependent on the geometry and less dependent on the breathing pattern. The results of PDA measurements are presented in [15] in more detail. 


\section{SEGMENTED MODEL FOR DEPOSITION MEASUREMENTS}

The geometry of the segmented model is identical to the model for optical measuring methods. Contrary to the previous model, segmented model is fabricated directly as a positive by different Rapid Prototyping Method. The model was created following way: First we created an envelope 1-5 mm thick round the initial airway geometry, and then flanges were added to the parts of the model to $4^{\text {th }}$ generation to provide connection of segments with screws. The remaining segments ( $4^{\text {th }}$ to $7^{\text {th }}$ generation) are all made up of two parts: the top part, which contains the actual airways; and lower part, which provides down-lead to the output. Model segments from larynx to the fourth generation of branching were produced by stereolithographic machine Viper (3D Systems). Thickness of one layer of material Watershed XC 11122 was $0.1 \mathrm{~mm}$, which is the default setting. The machine enables to set the printing layer to a thickness of $0.02 \mathrm{~mm}$. Segments from $4^{\text {th }}$ to $7^{\text {th }}$ generation were made on the machine Eden 250 (Objet Geometries) from material FullCure by Polyjet technology, thus creating a complete model of the lungs to the seventh generation of branching. It is possible to connect segments from $4^{\text {th }}$ to $7^{\text {th }}$ generation of branching to a model for optical measurements. The whole model consists of 22 parts what facilitates detailed evaluation of local deposition.

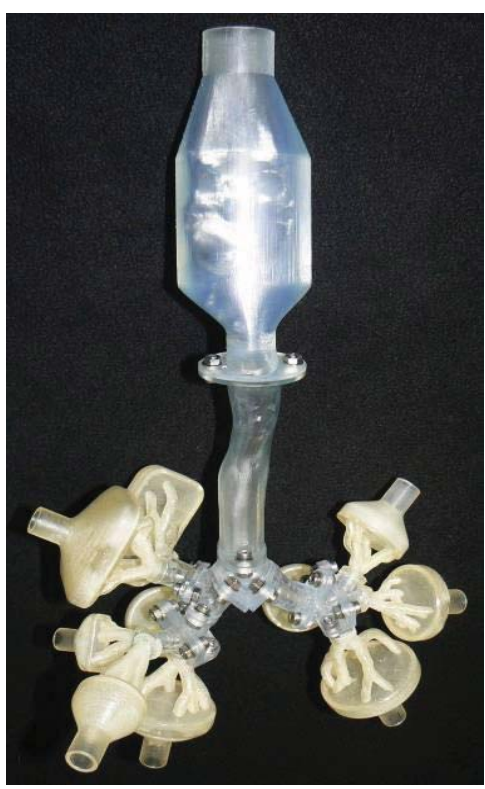

Figure 8 The model for measurement of deposition

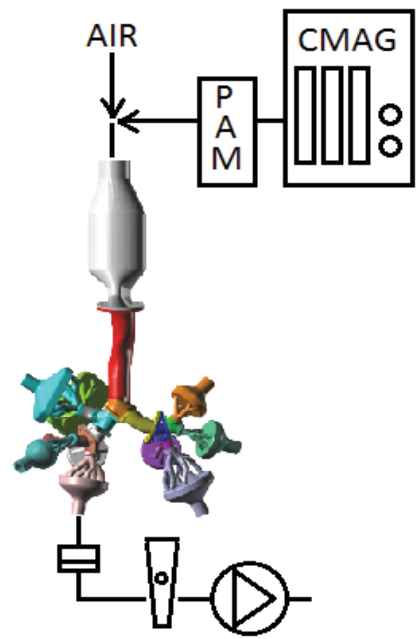

Figure 9 Scheme of the test rig for measurements of deposition

\section{EXPERIMENTAL SETUP FOR DEPOSITION MEASUREMENTS}

Aerosol deposition in the model of human airways was evaluated by fluorescence based method. We used DEHS particles in sizes $1 \mu \mathrm{m}, 3 \mu \mathrm{m}$ and $6 \mu \mathrm{m}$ and three static inspiration regimes 15 LPM, 30 LPM and 60 LPM, which were provided by vacuum pump. Mean Reynolds number of used static regimes matches mean Reynolds number for cyclic regimes used for PDA measurements. Distribution of flowrates to particular branches was 
set according to Table 1 . The values come from prior measurements of flowrate distribution in a model of lungs during cyclic breathing regimes.

Experimental stand consists of Condensation monodisperse aerosol generator TSI 3475 (CMAG), Process Aerosol Monitor TSI 3375 (PAM) for measurement of size and concentration of particles, segmented model, 10 filters Millipore AAWP 025 00, 10 flowmeters and a vacuum pump (see Fig. 9). Tightness of the model was ensured by applying of sanitary silicone to all connections and proved by leakage test before each experiment.

\section{Table 1 Distribution of flow in output branches}

\begin{tabular}{|c|c|c|c|c|c|c|c|c|c|c|c|}
\hline Output (\#) & 23 & 24 & 25 & 26 & 27 & 28 & 29 & 30 & 31 & 32 & $\begin{array}{c}\text { Total flow } \\
\text { (LPM) }\end{array}$ \\
\hline \multirow{3}{*}{ Flowrate (LPM) } & 2.7 & 3.3 & 8.0 & 3.9 & 7.1 & 9.3 & 7.6 & 6.2 & 6.1 & 5.9 & 60 \\
\cline { 2 - 12 } & 1.4 & 1.7 & 4.0 & 2.0 & 3.6 & 4.7 & 3.8 & 3.1 & 3.1 & 3.0 & 30 \\
\cline { 2 - 12 } & 0.7 & 0.8 & 2.0 & 1.0 & 1.8 & 2.3 & 1.9 & 1.6 & 1.5 & 1.5 & 15 \\
\hline
\end{tabular}

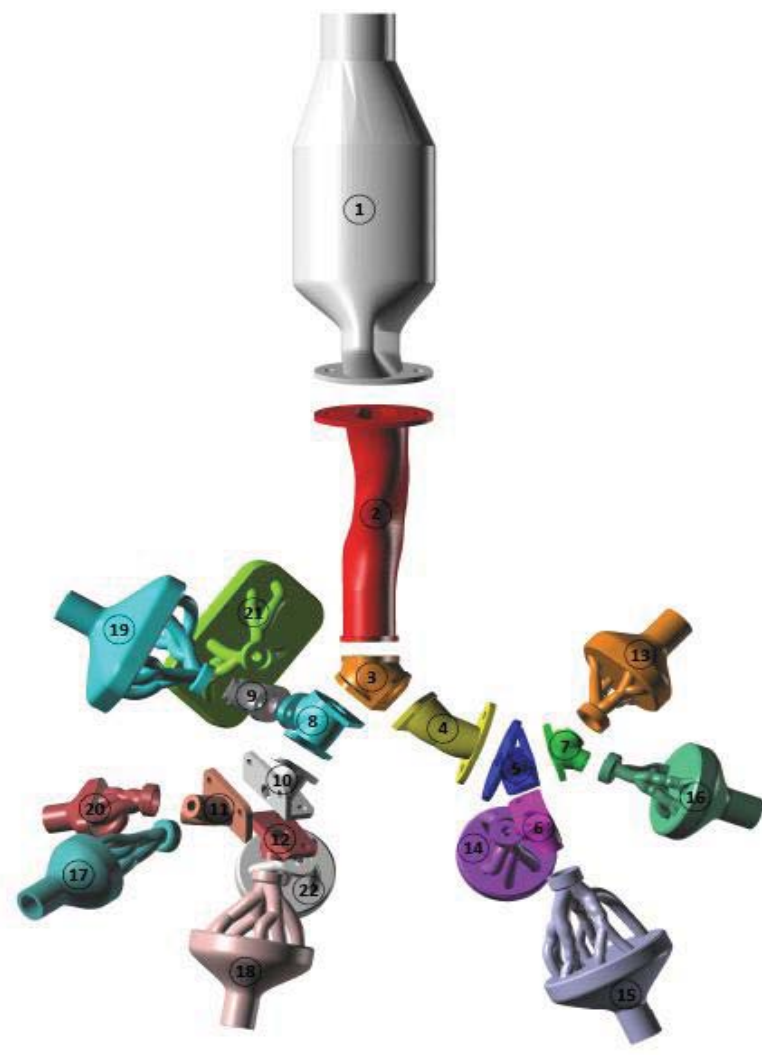

Figure 10 Numbering of segments of the model for deposition
After each experiment filters and all segments were separately placed to beaker with certain amount of isopropanol and sonicated for 10 minutes to dissolve deposited DEHS particles into isopropanol. 32 samples from each experiment were created in that manner (22 segments and 10 filters). Furthermore blank sample (isopropanol) and two samples with DEHS (before and after the experiment) were created.

Samples were then analysed by spectrometer at Faculty of Chemistry, Brno University of Technology. Data for correction of absorption were acquired by UV-VIS spectrometry of each sample. Captured fluorescence intensities which correspond to the amount of deposited DEHS in the segment were then corrected for light absorption, blank sample and spectrometer sensitivity. Resulting corrected intensities were conversed to deposition fraction, deposition efficiency and deposition density.

\section{RESULTS OF DEPOSITION MEASUREMENTS}

Deposition fraction is the ratio of amount of deposited aerosol in the segment to the total amount of inhaled aerosol. Deposition efficiency is the ratio of the amount of deposited aerosol in the segment to the amount of aerosol entering the segment. Deposition density is the ration of the amount of deposited aerosol in the segment to the surface 
area of the segment. Due to limited space only results for airflow 30 LPM, $3 \mu \mathrm{m}$ particles and 3 repetitions and 15 LPM and $3 \mu \mathrm{m}$ are presented.

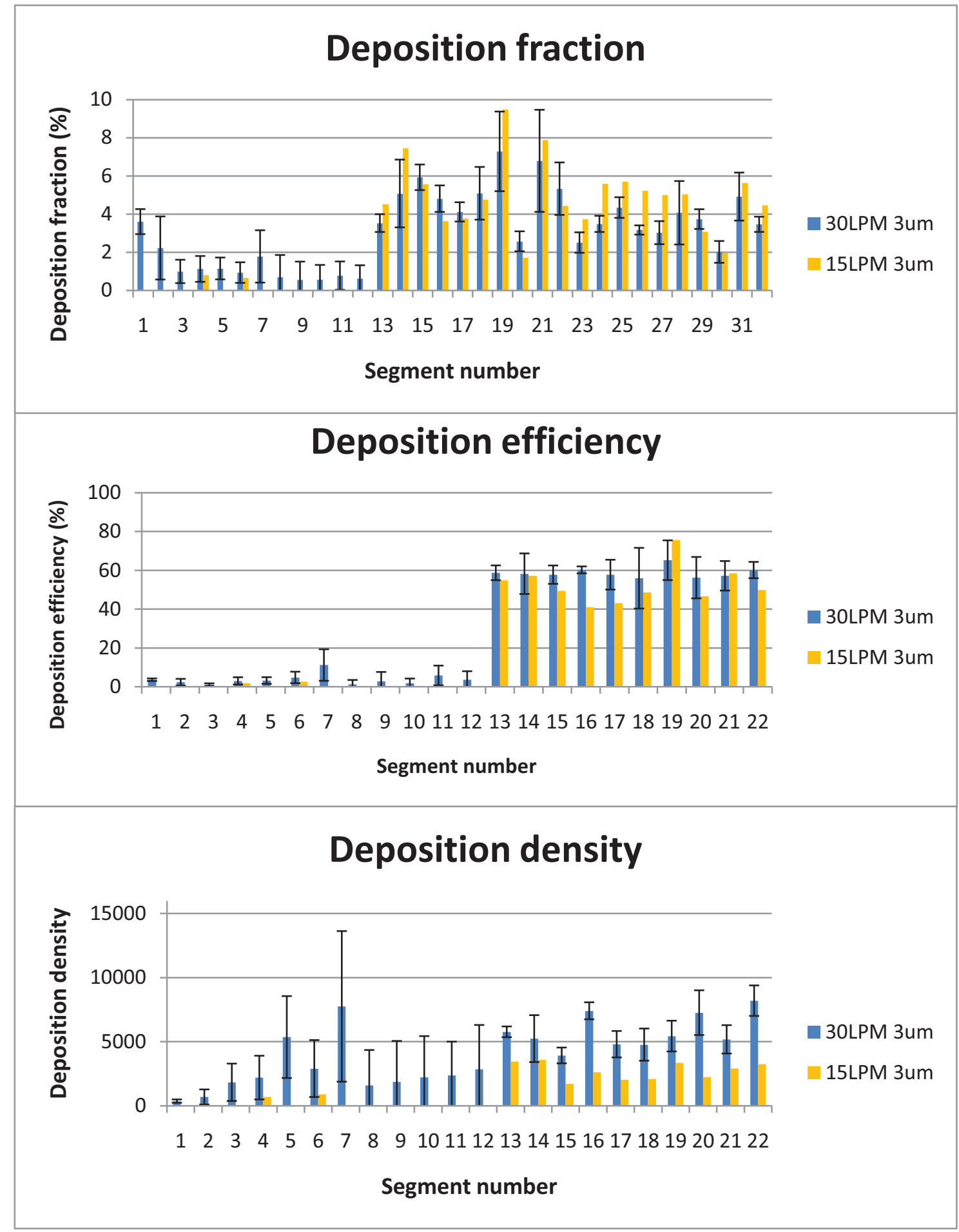

Figure 11 Deposition fraction, deposition efficiency and deposition density

\section{Discussion}

It is evident from deposition fraction and deposition efficiency charts that segments 1 to 12 show significantly lower deposition than segments 13 to 22 . There are several 
possible reasons: the surface area of the latter segments is larger and the latter segments also include multiple bifurcations, which are always places of deposition hot spots. The first assumption is supported by deposition density chart which documents significant equilibration of deposition if total amount of deposited aerosol is divided by surface area. Highest (resp. lowest) deposition fraction was found in segment 19 (resp. 20) which has a large (resp. small) surface area. However, their deposition density values are comparable.

Also the second assumption is supported by deposition density chart, because e.g. the segment 3, which includes a bifurcation, has higher density than segment 2, despite the same inlet diameter.

Other possible explanation of so high deposition fraction in segments 13 to 22 is related to surface quality of segments. Segments 13 to 22 were fabricated from different material which could have different properties. To exclude this possibility we fabricated a new model with all segments made from the same material.

It is likely that deposition is a function of flowrate, what is apparent from charts of deposition fraction for 15 LPM namely in segments 1 to 12 . Confirmation of this hypothesis demands analysis of remaining samples for 15 LPM and 60 LPM.

Measurement of velocity and intensity of velocity fluctuations by PDA unambiguously evidenced that flow field is extremely influenced by both upstream and downstream airway geometries. It means that reliable results could be achieved only in measuring points farther from outlets. The fact that the velocity course is highly dependent on the geometry and less dependent on the breathing pattern is substantial for targeted drug delivery. Intensity of velocity fluctuations is higher during expiration, due to mixing of airflow from daughter branches.

\section{CONCLUSION}

The results evidenced that geometry of the model significantly influences the flow field and consequently the deposition. In this regard it appears to be an advantage having the complete realistic geometry of the segmented model to $7^{\text {th }}$ generation of branching. The deposition density seems to be better characteristics than deposition fraction and deposition efficiency to compare deposition in different segments of the human airway model. Further analysis of measurements is ongoing where results for spherical particles deposition will be compared with results of fiber deposition.

\section{ACKNOWLEDGEMENT}

The authors gratefully acknowledge a financial support from the project GA101/09/H050 funded by the Czech Science Foundation, projects ME 09030 of the program KONTAKT, and from the project BD13001007.

\section{REFERENCES}

[1] Adler K., Brücker C.: Dynamic flow in a realistic model of the upper human lung airways, Experiments in Fluids, vol. 43, no. 2-3, 2007, pp. 411-423.

[2] Brücker C., Schröder W.: Flow visualization in a model of the bronchial tree in the human lung airways via 3-D PIV, In: Proceedings of PSFVIP-4, Chamonix, France, 3-5 June 2003. 
[3] Chang H.K., El Masry O.A.: A model study of flow dynamics in human central airways. Part I: Axial velocity profiles, Respiration physiology, vol. 49, no. 1, 1982, pp. 75-95.

[4] Cheng Y.-., Zhou Y., Chen B.T.: Particle deposition in a cast of human oral airways, Aerosol Science and Technology, vol. 31, no. 4, 1999, pp. 286-300.

[5] Clinkenbeard R.E., Johnson D.L., Parthasarathy R., Altan M.C., Tan K.-., Park S.-., Crawford R.H.: Replication of human tracheobronchial hollow airway models using a selective laser sintering rapid prototyping technique, American Industrial. Hygiene Association Journal, vol. 63, no. 2, 2002, pp. 141-150.

[6] Corcoran T.E., Chigier N.: Characterization of the laryngeal jet using Phase Doppler Interferometry, Journal of Aerosol Medicine: Deposition, Clearance, and Effects in the Lung, vol. 13, no. 2, 2000, pp. 125-137.

[7] Corcoran T.E., Chigier N.: Inertial deposition effects: A study of aerosol mechanics in the trachea using laser doppler velocimetry and fluorescent dye, Journal of Biomechanical Engineering, vol. 124, no. 6, 2002, pp. 629-637.

[8] Corieri P., Riethmulle, M.L.: Laser Doppler velocimetry and computer automation to measure low velocities in a pulmonary model, ICIASF Record, International Congress on Instrumentation in Aerospace Simulation Facilities, 1989, pp. 226-236.

[9] Gemci T., Corcoran T.E., Chigier N.: A numerical and experimental study of spray dynamics in a simple throat model, Aerosol Science and Technology, vol. 36 , no. 1,2002 , pp. 18-38.

[10] Guilmette R.A., Wicks J.D., Wolff R.K.: Morphometry of human nasal airways in vivo using magnetic resonance imaging, J.Aerosol Med., vol. 2, no. 4, 1989, pp. 365-377.

[11] Gurman J.L., Lippmann M., Schlesinger R.B.: Particle deposition in replicate casts of the human upper tracheobronchial tree under constant and cyclic inspiratory flow. I. Experimental, Aerosol Science and Technology, vol. 3, no. 3, 1984, pp. 245-252.

[12] Hopkins L.M., Kelly J.T., Wexler A.S., Prasad A.K.: Particle image velocimetry measurements in complex geometries, Experiments in Fluids, vol. 29, no. 1, 2000, pp. 91-95.

[13] Horsfield K., Dart G., Olson D.E., Filley G.F., Cumming G.:, Models of the human bronchial tree, Journal of applied physiology, vol. 31, no. 2, 1971, pp. 207-217.

[14] Isabey D., Chang, H.K.: A model study of flow dynamics in human central airways. Part II: Secondary flow velocities, Respiration physiology, vol. 49, no. 1, 1982, pp. 97-113.

[15] Jedelský J., Lízal F., Jícha M.: Particle Motion in a Realistic Human Airway Model under Steady and Cyclic Flows, In proceedings XXIV. Symposium on Anemometry, Praha, Institute of Hydrodynamics ASCR, 2010.

[16] Lieber B.B., Zhao Y.: Oscillatory flow in a symmetric bifurcation airway model, Annals of Biomedical Engineering, vol. 26, no. 5, 1998, pp. 821-830.

[17] Lízal F.: Experimentální výzkum transportu a depozice aerosolů $v$ dýchacím traktu člověka, Discourse on the Dissertation Thesis, Brno, Odbor termomechaniky a techniky prostředí FSI VUT v Brně, 2010. 
[18] Menon A.S., Weber M.E., Chang H.K.: Model study of flow dynamics in human central airways. Part III: Oscillatory velocity profiles, Respiration physiology, vol. 55, no. 2, 1984, pp. 255-275.

[19] Peattie R.A., Schwarz W.: Experimental investigation of oscillatory flow through a symmetrically bifurcating tube, Journal of Biomechanical Engineering, vol. 120, no. 5, 1998, pp. 584-593.

[20] Raabe O.G., Yeh H.C., Schum G.M., Phalen R.F.: Tracheobronchial geometry: Human, dog, rat, hamster, Albuquerque, NM, Lovelace Foundation Report, LF53, 1976, http://mae.ucdavis.edu/wexler/lungs/LF53-Raabe/ (accessed January 2010).

[21] Ramuzat A., Riethmuller M.L.: PIV investigations of oscillating flows with a 3D lung multiple bifurcation model, 11th Int.Symp.on Appl.of Laser Techniques to Fluid Flows, 2002, pp. 8-11.Rubin B.K.: Other medications for aerosol delivery, Paediatric Respiratory Reviews, vol. 7, no. SUPPL. 1, 2006, pp. S76-S79.

[22] Rubin B.K.: Other medications for aerosol delivery, Paediatric Respiratory Reviews, vol. 7, no. SUPPL. 1, 2006, pp. S76-S79.

[23] Schmidt A., Zidowitz S., Kriete A., Denhard T., Krass S., Peitgen H.-.: A digital reference model of the human bronchial tree, Computerized Medical Imaging and Graphics, vol. 28, no. 4, 2004, pp. 203-211.

[24] Siekmeier R., Scheuc, G.: Inhaled insulin - does it become reality?. Journal of Physiology and Pharmacology, vol. 59, no. SUPPL. 6, 2008, pp. 81-113.

[25] Tanaka G., Ogata T., Oka K., Tanishita K.: Spatial and temporal variation of secondary flow during oscillatory flow in model human central airways, Journal of Biomechanical Engineering, vol. 121, no. 6, 1999, pp. 565-573.

[26] TSI.: Model 3475 Condensation Monodisperse Aerosol Generator, Shoreview, USA, Instruction Manual, TSI Incorporated, 2004.

[27] Weibel E. R.: Morphometry of the Human Lung, New York, Berlin, Springer Verlag and Academic Press, 1963.

[28] Zhou Y., Cheng, Y.-.: Particle deposition in a cast of human tracheobronchial airways, Aerosol Science and Technology, vol. 39, no. 6, 2005, pp. 492-500. 